\title{
The Effectiveness of Cooperative Learning Activities in Enhancing EFL Learners' Fluency
}

\author{
Hassan Alrayah ${ }^{1}$ \\ ${ }^{1}$ Taif University, KSA \\ Correspondence: Hassan Alrayah, Taif University, KSA. E-mail: hasanalrayah@yahoo.com
}

Received: November 4, 2017 Accepted: March 10, 2018 Online Published: March 12, 2018

doi: $10.5539 /$ elt.v11n4p21

URL: http://doi.org/10.5539/elt.v11n4p21

\begin{abstract}
This research-paper aims at examining the effectiveness of cooperative learning activities in enhancing EFL learners' fluency. The researcher has used the descriptive approach, recorded interviews for testing fluency as tools of data collection and the software program SPSS as a tool for the statistical treatment of data. Research sample consists of (48) first year-students, studying English language in the Faculty of Education at Omdurman Islamic University-Sudan. The students were divided into experimental and control groups for the requirement of the research-paper. The program of the experimental group lasted for a whole month in which much practice was conducted through the Cooperative Learning activities for enhancing the experimental group's fluency. The most important result indicates a statistically significant correlation between the Cooperative Learning activities and the improvement of EFL learners' oral fluency of speaking. The most important recommendation addresses the concerned authorities to train EFL teachers in the use of Cooperative Learning activities in the teaching/learning process for the purpose of furnishing to generalize their use in the various institutions where English language is studied.
\end{abstract}

Keywords: jigsaw, round robin, numbered heads together, learning activities

\section{Introduction}

Based on the researcher's experience in English language teaching at the university level, he ascertains that, EFL learners are introduced to rich courses of English language throughout the academic sessions in the university. The prescribed courses are well-designed to contribute positively in promoting EFL learners' communicative competence and meanwhile, reasonable time is devoted to the achievement of such courses. Simultaneously, the researcher notices that, among the finalist and semi-finalist students, there are students who still find it difficult to communicate their ideas or express themselves in fluent English. However, students on the lower levels, struggle with their spoken English even in simple tasks and in this sense, fluency is rarely observed.

However, incapability of communicating fluently, easily and normally, constitutes a psychological barrier that eventually reduces students' effective interaction in foreign language learning-contexts. Such a problem affects negatively students' academic achievements and casts dim shadows on their future working-opportunities as well. And, for these reasons, this research paper seeks to address this special problem by attempting to answer the following question:

To what extent the Cooperative Learning Activities are effective in improving oral fluency of speaking to the EFL learners in the university level?

\subsection{Significance}

The significance of this study is its attempt in realizing the concepts of the Cooperative Learning Activities, particularly in improving EFL learners' oral fluency of speaking. On the other hand, fluency constitutes a top target for EFL learners who struggle to achieve it. EFL learners hope to get their messages across smoothly, easily and reasonably fluently without having to stop or pause a lot, meanwhile communication is the most essential part of speaking and it is important to communicate one's ideas as naturally as possible.

If the final results of investigation are positive, the research-paper will apparently contribute in enhancing fluency, which is a desirable target. 


\subsection{Objective}

The aim of this research-paper is to investigate: the correlation between the Cooperative Learning Activities and the improvement of oral fluency of speaking to the EFL learners in the university level.

Moreover, the research-paper seeks to contribute scientifically in the field of developing English language as a foreign tongue.

\subsection{Preamble}

Cooperative Learning is an old approach in the teaching/learning process as Johnson: (1991) reports: "In the late 1700s, Joseph Lancaster and Andrew Bell used cooperative learning groups extensively in England, and the idea was brought to the United States when a Lancastrian school was opened in New York City in 1806." This shows the deep roots of the Cooperative Learning, and since that time there have been various stages of developments which have situated it among other approaches and methods of the teaching/learning process. The Cooperative Learning now has its unique definitions, concepts, theories and applications in terms of methods and techniques, which are explored in the following lines.

\subsection{Definitions of Cooperative Learning}

Scholars have defined cooperative learning in various terms, among these definitions:

1) Johnson's Definition

Johnson (1991) states: "Cooperative learning is the instructional use of small groups so that students work together to maximize their own and each other's learning. Students exert their effort to have each other information in order to enhance learning."

2) Richards' Definition

Richards, (1992) points out that: "Cooperative Learning is an approach to teaching and learning in which classrooms are organized so that students work together in small cooperative teams".

3) Jordan's Definition

Jordan, (2010) defines CL as follows: "Cooperative learning, an effective educational practice in many situations, has sometimes been proposed as the magic bullet to solve the educational debate."

4) Elizabeth's Definition

Elizabeth, (2004) concludes that: "Cooperative learning is both a philosophical position and a set of teaching strategies."

\subsection{Exploring the Definitions}

The definitions reflect that, Cooperative Learning is a teaching strategy in which small teams of students use a variety of learning activities to improve their understanding of a subject. Each member of a team is responsible not only for learning what is taught but also for helping teammates learn, thus creating an environment of achievement and practice is required. In this sense, all members of a team work together to produce a common product and even if the members are of different levels of abilities. Now, and with reference to the above-mentioned definitions, associated with the objectives of this research-paper, the researcher comes out with the following operational definition:

\subsection{Operational Definition}

Cooperative Learning might broadly be defined as any classroom learning situation in which students of all levels of performance work together in structured groups toward a common goal. In the competition with every other individual in the classroom, students are given the accountability of creating a learning community where all students participate in a significant and meaningful way.

\subsection{Cooperative Learning Theories}

Cooperative Learning is well-grounded by three famous theories:

1) Social Interdependence Theory

2) Classical Learning Theory

3) Individual Differences Theory

\subsection{Social Interdependence Theory}

Social interdependence theory is a classic instance of the interaction theory, research and practice. The basic idea 
of the theory is the way in which goals are structured and how individuals interact, which in turn creates outcomes. Johnson and Johnson, (1989) claim that, "There are two types of social interdependence: positive, when the actions of individuals promote the achievement of joint goals, and negative, when the actions of individuals obstruct the achievement of each other's goal." Their ideas show that, positive interdependence exists when individuals understand that they can attain their goals if the other individuals with whom they are cooperatively linked also attain their goals and, therefore, promote each other's efforts to achieve the goals. Negative interdependence exists when individuals understand that they can obtain their goals if the other individuals with whom they are competitively fail to gain their goals and, therefore, disrupt each other's efforts to achieve the goals.

Therefore, positive interdependence results in promoted interaction, negative interdependence results in oppositional interaction, and no interdependence results in the absence of interaction. Promoted interaction can be referred to as individuals supporting and facilitating each other's efforts to complete tasks, achieve, or produce in order to attain the group's goals.

A number of researches point out that, cooperative learning efforts resort to promote greater efforts to realize positive relationships. Power of cooperation depends on the existence of positive interdependence that results in encouraging action and interaction. In application of Social Interdependence Theory, there is major evidence that cooperative efforts tend to promote big efforts to achieve more positive relationships, and greater psychological health than do competitive or individualistic efforts.

Furthermore, the power of cooperation has been shown to rely on the presence of clear, positive interdependence, which includes individual accountability that results in promoted interaction that involves appropriate use of social skills and group processing. These consequences provide strong confirmation of social interdependence theory, as the validating research encompasses considerable diversity and generalizability. Having a supported theory, however, does not imply that it will direct or even influence practice. Effective practices can be derived from sound theories, but they can also be validly derived from unsound theories or from no theory at all. Moreover, effective practice can be derived from validated theory only if the theory is stated with sufficient accuracy that effective procedures can be deduced for practitioners to use.

\subsection{Classical Learning Theory}

Classical learning theory encompasses four dimensions:

1) Reinforcement

2) Correction opportunity

3) Practice opportunity

4) Transference

\subsection{Reinforcement}

Kagan and Miguel (2009) claim that, "when behaviour is followed by a reward, it is more likely to be repeated." According to the quote, if a teacher asks a student to write five papers for a year versus a considerable prize from now, this would not motivate him much, but if the teacher asks the same student to write five papers at present versus a small prize, this motivates the student more than the first one.

Therefore, better to change from delayed reinforcement to frequent reinforcement and from a smoothly desirable reward to highly desirable reward. Cooperative learning increases the immediacy of rewards, the desirability of rewards for accomplishment.

\subsection{Correction Opportunity}

Students are more likely to find feedback from their classmates than from their teacher. Cooperative learning converts the dynamics of correction opportunities similar to reinforcement.

In cooperative learning, correction is immediate, frequent, more equal, and supportive.

\subsection{Practice Opportunity}

The traditional view is to maximize teacher's talking time and minimize students' talking time. However, cooperative learning accounts for the opposite: to minimize teacher's talking time and maximize students' talking time.

\subsection{Transference}

The amount of transference relies on the similarity of the situation of acquisition and the situation of the later 
performance. In the traditional classrooms, students seat in rows and work alone. This structure is very different in teams and is unlike other social interaction situations. Cooperative teams are social interaction positions, so the situation of acquisition is a resemblance to the situations in which the students implement the skills they have learnt. Cooperative learning works well because it decreases the transference gap. When cooperative learning in its place, students are learning skills such as those they will need in life.

\subsection{Individual Differences Theory}

Individual differences are the differences from one person to another on variables such as multiple intelligences, learning style and cognitive development. Students have different minds and learn in different ways. However, the most important differences are multiple intelligence and learning styles. Freeman, (2000) argues that: "In the language teaching field, some of the differences among students have been attributed to students' having different learning or cognitive styles".

According to Freeman, some learners are better visually than those who listen to a material or it depends on the structures related to multiple-intelligence. This covers linguistic or verbal structures as debate, dialogues, discussion and team interview.

In his on line magazine (Kagan, 1998) mentions that: "There are important connections between cooperative learning and multiple intelligences." He puts emphasis on simple multiple intelligences instructional strategies which can be incorporated as part of any lesson. Simple, instructional strategies can be easily integrated into any lesson to release the power of cooperative learning and multiple intelligences.

Watkins, et al. (2007) argue that: "The attraction of learning styles is understandable. It reminds teachers that young people learn in different ways, and that activities for learning should be varied." They state that, students vary in their learning style, and the idea that people differ in ability is not controversial everyone agrees with that Some people are good at dealing with conversations; some people have good ideas in convincing others, so the idea of style actually ought to mean something different.

Joliffe, (2007) explains that: "There is a danger of regarding this too simplistically and thinking of individuals as having fixed learning styles."

Beside the valuable ideas which are involved in the above-mentioned theories, the researcher advocates the use of a variety of teaching techniques to give all students the best chances for practicing the language and so fluency is enhanced.

\subsection{Cooperative Learning and Communicative Competence}

Cook, (2003) indicates that: "Directly or indirectly, the notion of communicative competence has been very widely drawn upon in all areas of applied linguistics." He states that, "the concept of communicative competence is widely used and encompasses different areas". The Cooperative Learning Activities concern teaching and learning processes it is the area of applied linguistics. Therefore, both cooperative learning and communicative competence are integral ideas in ELT, since they provide learning dimensions.

When students interact in cooperative learning groups, they learn to give and take information, develop new concepts and perspectives in language, and communicate in a socially acceptable manner. Through interacting with each other in reciprocal discussions students learn to use language differently to explain new experiences.

It is important to realize how Cooperative Learning Activities can contribute to attaining better learning results in foreign language learning regarding the speaking competence. In this context, an important criterion is how much output the individual student is given the chance of producing, since it is here that a very central part of language acquisition and communicative competence in general takes place. Brown (2000) supports the idea by saying: "Another important issue in describing communicative competence is the way we use language in different styles depending on the context of a communicative act in terms of subject matter, audience, occasion, shared experience, and purpose of communication". According to this quotation, classroom goals are all of the components of communicative competence and not confined to grammatical or linguistic competence. Language techniques are designed to engage learners in the pragmatic, authentic, functional use of language for meaningful purposes. Organizational language forms are not the central focus but rather aspects of language that enable the learner to accomplish those purposes.

Fluency and accuracy are seen as complementary principles underlying communicative techniques. At times fluency may have to take on more importance than accuracy in order to keep learners meaningfully engaged in language use. In the communicative classroom, students ultimately have to use the language, productively and receptively, in unrehearsed contexts. 
Kagan and Miguel (2009) say "Students are more communicative in the cooperative classroom and develop their communication skills so they are more capable of talking out and peacefully resolving conflicts." That is to say, the students who study the language using cooperative learning, manage to train many different components of communicative competence. Strategic competence is used in the negotiation of meaning that takes place in the endeavor to be understood by others; pragmatic competence concerns the use of speech-acts that otherwise do not occur all that frequently in teaching situations such as praising, giving advice, asking clarifying questions.

Discourse competence is at the very center of inside and outside-circle, both when they are listening to the structure of the presentation and when giving feedback to it, and when discussing the structure in teams. All aspects of at least the oral side of communicative competence are involved when one works through cooperative learning.

\subsection{Advantages of Cooperative Learning}

Cooperative learning has social benefits as well as academic. One of the essential elements of cooperative learning is the development of social skills such as communicating, building confidence, providing leadership, and managing conflicts, such skills contribute to the general contentment of learning.

Students work with classmates who have different learning skills, cultural background, attitudes, and personalities. Watkins, et al. (2007) Mention that in the first step of cooperation, and when learners explain their meaning-making to each other, they enrich their knowledge, make sense of challenges and communicate in such a way that their own understanding is consolidated. Watkins, et al emphasize the importance of explaining the students own concepts to each other and this foster many social skills and knowledge. In addition to that, the variation of responses to the relevance of group activities is at least partially explained by the fact that individual students are referring to their personal experiences of noticeably different approaches to the structuring of group learning.

Other benefits of the Cooperative Learning Activities can be obtained from mixed-ability classes. Many studies indicate that mixed-ability grouping is the most effective way to maximize student success. When students are in mixed-ability groups, teachers can make use of advantages of cooperative learning and peer tutoring, resulting in positive learning experiences for all learners. As students interact with other students of different developmental levels, other students become more excited about learning and make significant gains, as they have the support and the encouragement from the students of higher levels, as well as the exposure to the knowledge and work of those students.

The most able students also make significant gains as they assume leadership roles, and explain their own ideas while explaining material to others. Leo Jones (2007) mentions that: "In many ways, every class is a mixed-ability class. Even students who have studied together all the time will have varied mastery of the language or remember different things". The researcher thinks that the notion of mixed ability classes are not of great importance and the idea is so vague and poor expectations in terms of accountability and eschewal of teaching that is to say the role of the teacher is poor. In this case, some students pay attention are cooperative, others misbehave and seem disinterested. Furthermore, teachers feel concerned that they are not challenging the high-achievers enough and at the same time are not giving enough help to those who are not doing as well. So, what is mentioned is a clear rejection of saying there are advantages to Cooperative Learning Activities. Additionally, every student has a different way of learning, also learns and progresses at different speeds. Thus, while some students may find the learning task very easy to deal with, others may find it difficult to understand.

The researcher believes in that, when students are involved into the cooperative learning activities, they explain things better to each other. Students learn how to teach one another and explain material in their own words, questions are more likely to be asked and answered in a group setting, and positive interdependency is carried out as individuals feel that they cannot succeed unless everyone in their group succeeds.

\subsection{Cooperative Learning Activities}

Cooperative learning has special activities that can foster peer interaction, which on the other hand, helps the development of communicative language and the learning of notions and content.

Wendy Joliffe (2007) asserts that: "Providing cooperative learning opportunities for learners in pairs and small groups can ensure that learners talk meaningfully and in relation the task." The cooperative learning activities are large in number; however, the researcher has chosen the following: (Jigsaw - Round Table and Round Robin - Three-Step Interview - Role-Play -Numbered Heads Together - Think-Pair-Share - Carousel Brainstorming). 


\section{1) Jigsaw}

Jigsaw is a cooperative learning activity that aims to decrease conflict and consolidating positive educational outcomes. The jigsaw activity helps students realize that they are essential components of a whole and encourages cooperation in a learning situation. Brown, (2001) emphasizes that: "Jigsaw activities are a special form of information gap in which each member of a group is given some specific information". Accordingly, students gather in a topic-group that contains many students with the same piece to study the material, then, they classify the information through discussion.

\section{2). Round Table and Round Robin}

According to Tony (1996), "Round Table and Round Robin are extremely important cooperative learning structures. In essence, students take turns contributing to the group in an oral form for Round Robin and a written form for Round Table." They explain that both activities are important: in Round Table, learners take turns articulating and writing down ideas on a sheet of paper.

One of the strengths in Round Table is that, each learner in a group has an equal chance to participate in the creation of ideas. The kind of structures are brainstorming, containing learner question generation, stimulation of ideas, solutions to a problem, posing possible answers to an open-ended question, information recall and so forth. In Round Robin, an important goal of brainstorming is to create as many ideas as possible without assessing them. The use of a Round Robin structure not only gives each person an equal chance to create an idea, it also hinders evaluative talk during the process.

\section{3). Three-Step Interview}

Holt (199) explains the Three-Step Interview in a way that, each person must produce and receive language. There is an equal participation and individual accountability for listening, because in the third step each student shares what he or she has heard." Thus, there are deep differences between obviously similar simple cooperative structures. Three-Step Interview is far better for improving spoken and listening skills as well as for promoting equal participation.

4). Role-Play

According to the researcher's experience, the Role-Play gets participants actively involved communicative tasks.

5). Numbered Heads Together

Learners have the chance to develop some ideas or responses to a question through discussion. When the discussion is concluded, learners are randomly selected to sum up small group discussion. Numbered Heads Together is an effective activity for assessing prior knowledge on a topic at the beginning of a unit or to check understanding after learners have gathered information about a topic.

\section{6). Think-Pair-Share}

Think-Pair-Share is an activity that allows students engage in individual and small-group thinking before they are asked to answer questions in front of the class. There are four steps to this activity:

a. Groups of four students listen to a question posed by the teacher.

b. Individual students are given time to think and then write their responses.

c. Pairs of students read and discuss their responses.

d. The teacher calls some students to share their thoughts and ideas with the whole class.

7). Carousel Brainstorming

Carousel Brainstorming actively joins groups in brainstorming multiple ideas. Moreover, the structure contains movement, which helps stimulate the mind and meets the needs of kinesthetic learners. There are different types of brainstorming, including learner question generation, stimulation of ideas, solutions to a problem, posing possible answers to an open-ended question, information recall and so forth:

\section{Methodology}

Approach: The descriptive approach

Tools of data collection: Recorded interviews for testing fluency.

The recorded data consists of (96) interviews produced as oral answers to pre- and post-tests by (48) first year-students in the Faculty of Education at Omdurman Islamic University.

Tools of data analysis: SPSS software program for statistical treatment of data 
Population: (48) First year-students, studying English language in the Faculty of Education at Omdurman Islamic University/ Sudan. The students were divided into experimental and control groups, (24) for each groups. The experimental group was involved into practice of English language for a whole month. All prescribed topics were conducted through the aforementioned Cooperative Learning activities.

\section{Results}

The aim of data analysis and discussion is to give a clear answer for the research-paper one question in a way to reflect the findings in a scientific way. The question is: (To what extent the Cooperative Learning Activities are effective in improving oral fluency of speaking to the EFL learners in the university level?)

According to the recorded interviews by first year-students in the Faculty of Education at Omdurman Islamic University, specific items for checking fluency, have been examined and assessed through pre- and post-tests. The items include:

a. The use of a variety of vocabulary and expressions. (V\& Ex)

b. The use of variety of grammatical structures. (G St)

c. Smooth speaking. (S Sp)

d. Effective communication. (E Co)

e. Accurate pronunciation and clear intonation. (P \& In)

(The abbreviations represent the statements in the following)

For the answer of the question, the following tables show students' marks in various fluency-tests:

Table 1. Comparing the results of pre-test for both control and experimental groups

\begin{tabular}{lll}
\hline Items & Control Group & Experimental Group \\
\hline The use of a variety of vocabulary and expressions & $14.9 \%$ & $15.0 \%$ \\
The use of variety of grammatical structures & $12.5 \%$ & $14.5 \%$ \\
Smooth speaking & $7.9 \%$ & $10.0 \%$ \\
Effective communication & $6.5 \%$ & $8.0 \%$ \\
Accurate pronunciation and clear intonation & $6.5 \%$ & $7.0 \%$ \\
Percentage & $48.30 \%$ & $54.5 \%$ \\
\hline
\end{tabular}

Table 1 does not show a clear statistical significance of one group in favor of the other. Both groups are nearly at the same level in the use of a variety of vocabulary and expressions and the use of variety of grammatical structures. This shows that students in both groups have mastered adequate knowledge but as far as fluency is concerned, both groups have low marks in the production of smooth speaking, effective communication, accurate pronunciation and clear intonation. However, the table shows that both groups have not achieved a good level in fluency.

Table 2. The mean scores of pre-test results for both groups

\begin{tabular}{|c|c|c|c|c|c|c|c|c|}
\hline Test & Group & $\mathrm{N}$ & Mean & $\begin{array}{c}\text { Std. } \\
\text { Deviation }\end{array}$ & $\mathrm{Df}$ & T. value & Sig & The result \\
\hline \multirow[t]{2}{*}{ Pretest } & $\begin{array}{c}\text { Experimental } \\
\text { Group }\end{array}$ & 24 & 5.3333 & .91683 & \multirow[t]{2}{*}{46} & \multirow[t]{2}{*}{1.758} & \multirow[t]{2}{*}{.085} & \multirow[t]{2}{*}{ No difference } \\
\hline & Control Group & 24 & 4.8333 & 1.04950 & & & & \\
\hline
\end{tabular}

The result in Table 2 states that there is no significant difference between the mean scores of the students' performance in the pretest for both experimental group and control group and this result indicates that the two groups are equal in the pretest of oral fluency of speaking. 
Table 3. Comparing the results of post-tests for the control and experimental groups

\begin{tabular}{llll}
\hline Items & C. Group & Ex. Group & Difference \\
\hline The use of a variety of vocabulary and expressions & $14.0 \%$ & $20.0 \%$ & $6.0 \%$ \\
The use of variety of grammatical structures & $13.5 \%$ & $20.0 \%$ & $6.5 \%$ \\
Smooth speaking & $9.5 \%$ & $16.7 \%$ & $7.2 \%$ \\
Effective communication & $8.0 \%$ & $11.3 \%$ & $3.3 \%$ \\
Accurate pronunciation and clear intonation & $7.5 \%$ & $10.0 \%$ & $2.5 \%$ \\
Percentage & $52.50 \%$ & $78.0 \%$ & $25.5 \%$ \\
\hline
\end{tabular}

Table 3 clearly indicates that the Experimental Group-result is far better than that of the Control in fluency tests. $25.5 \%$ constitutes a significant statistical difference.

Table 4. The mean scores of post-test results for both groups

\begin{tabular}{ccccccccc}
\hline Test & Group & $\mathrm{N}$ & Mean & $\begin{array}{c}\text { Std. } \\
\text { Deviation }\end{array}$ & D f & T. value & Sig & The result \\
\hline \multirow{2}{*}{ post test } & $\begin{array}{c}\text { Experimental } \\
\text { Group }\end{array}$ & 24 & 7.7917 & .65801 & & & \\
& Control Group & 24 & 5.2500 & 1.29380 & & 8.578 & .000 & $\begin{array}{c}\text { There is a } \\
\text { difference }\end{array}$ \\
\hline
\end{tabular}

The result in Table 4 states that there is statistically significant difference between the mean scores in the post test in favor of the experimental group. The $t-v a l u e ~(8.578)$ was significant at (.000) level. This result indicates that there is an improvement occurred to the students' level in oral fluency of speaking.

\section{Discussions}

The purpose of this research-paper is to investigate the effect of Cooperative Learning Activities in improving oral fluency of speaking in EFL to the students of the first year at Omdurman Islamic University at the English department.

The results of the investigation have proven that there is statistically significant difference between the mean scores of the experimental groups in pre and posttest. These results reflect that, the Cooperative Learning Activities have improved the oral fluency of speaking to the first-year students of Omdurman Islamic University. These activities include:
a. Three-Step-Interview
b. Think- Pair- Share
c. Jigsaw
d. Numbered Heads Together
e. Round Table
f. Carousel Brainstorming

The following techniques together, supported students to communicate in fluent English. They include:
a. The use of a variety of vocabulary and expressions
b. The use of variety of grammatical structures
c. Smooth speaking
d. Effective communication
e. Accurate pronunciation and clear intonation

When students implemented Cooperative Learning activities, it was noticed that there were valuable processes taking place. These are: 

a. Interaction
b. Active Discussion
c. Cooperation
d. Participation
e. Good Relationship

However, these processes proved to be of high value in the teaching/learning process.

Students learn from one another at a deeper level and feel better about themselves and their interactions with their peers. In addition, students learn valuable social skills. These skills are:
a. Resolving Conflict
b. Problem Solving
c. Criticizing Ideas And Not People
d. Paraphrasing
e. Asking Questions
f. Giving Direction to The Group's Work
g. Building on each other's Information.

Consequently, students consolidate their general knowledge.

The improvement of the students' level in oral fluency occurred as a result of continuous discussions among learners who usually enjoy working together because they are actively involved in the learning process.

Furthermore, the teacher's role changed from being in front of the room doing most of the work and all of the talking, to being a facilitator of learner learning, monitoring and collecting data on learner performance, as well as intervening when the group needs assistance in doing the task. The teacher openly encourages students to help each other and students share resources with each other, provide constructive feedback, challenge other members' reasoning and ideas, keep an opened mind, act in a trustworthy way, and promote a safe feeling for all by reducing anxiety.

In cooperative learning situations; there is a positive interdependence among students' goal to attain, they perceive that they can reach their learning goals if the other students in the learning group also reach their goals. So, students seek results that are beneficial to all those with whom they are cooperatively related.

Students discuss the material with each other, help one another understand it, and encourage each other to work hard, and of course this enhances their fluency of speaking. The results show that students were very much engaged to the mentioned ideas.

The development of the students in oral fluency of English happened not only of the activities but also of came as the result of another factor such as the nature of cooperative learning which includes basic elements.

Johnson (1984) clarifies the importance of these elements by saying that there are four basic elements that must be included for small group learning to be truly cooperative. The first is positive interdependence. This may be achieved through:
a. Mutual goals i.e., goal interdependence;
b. Divisions of work i.e., task interdependence
c. Dividing materials, resources, or informs on among group members i.e., resource interdependence,
d. Assigning students' different roles i.e., role interdependence
e. By giving joint rewards i.e., reward interdependence.

All these factors consolidate the position of Cooperative Learning Approach in terms of being effective. In order for a learning situation to be cooperative, teachers have to consider the following basic element of cooperative learning:

a. Students must perceive that they are positively interdependent with other members of their learning group.

b. Cooperative learning requires face-to-face interaction among students. It is the interaction patterns and verbal interchange among students promoted by the positive interdependence that affect education outcomes.

c. Individual accountability for mastering the assigned material is essential 
d. The purpose of a learning situation is to maximize the achievement of each individual student.

e. Determining the level of mastery of each student is necessary so students can provide appropriate support and assistance to one another.

Finally, and according to the results of the experimental group, cooperative learning requires that students appropriately use interpersonal and small-group skills. Obviously, placing socially unskilled students in a learning group and telling them to cooperate will not be successful. Students must be taught the social skills needed for cooperation and they must be motivated to use them.

Students must also be given the time and procedures for analyzing how well their learning groups are functioning and the extent to which students are employing their social skills to help all group members to achieve and to maintain effective working relationships within the group.

To sum up this discussion, students of the control group did not make notable signs of progress in fluency. Meanwhile, the students of the experimental group made a clear progress in their fluency. They were able to:

a. Express themselves freely

b. Interact purposefully with each

c. Avoid most types of hesitations

d. Avoid most of the psychological barriers in the learning context

e. Develop confidence

f. Feel happy and comfortable since using the language smoothly

g. Show desire for further practice in spoken English

Back to the Question:

To what extent the Cooperative Learning Activities are effective in improving oral fluency of speaking to the EFL learners in the university level?

The Answer: (Final Result)

With reference to all mentioned analysis and discussion, Cooperative Learning Activities are effective in improving oral fluency of speaking to the EFL learners in the university level.

\section{Recommendations}

Based upon the final result, the researcher addresses those who might concern to concider the following recommendations.

The Cooperative Learning Activities have to be generalized in teaching English as a foreign language

1) EFL teachers have to be trained in to use the Cooperative Learning Activities in the teaching/learning process

2) The difficulties that may face EFL teachers in applying the Cooperative Learning Activities in classrooms have to be anticipated and solved in advance.

\section{A Suggested Topic for Research}

Types of crash programs required for teacher-training in the domain of the Cooperative Learning.

\section{References}

Brown, H. (2000). Principles of Language Learning and Teaching. San Francisco: Longman Inc.

Cook, G. (2003). Applied Linguistics. Oxford: Oxford University Press. https://doi.org/10.1093/applin/24.2.249

Elizabeth, G. (2004). Teaching Cooperative Learning. The Challenge for Teacher Education. New york: State University of New York Press.

Freeman, D. (2000). Techniques and Principles in Language Teaching. Oxford: Oxford University Press.

Holt, D. (1993). Cooperative Learning: A Response to Linguistic and Cultural Diversity. Center for Applied Linguistics.

Johnson, W. J. (1989). Circles of Learning. Cooperation in the Classroom. University of Minnesota.

Johnson, D. W., Johnson, R. T., \& Karl, A. (1991). Cooperative learning: Increasing College Faculty Instructional Productivity. Washington. D.C: The George Washington University.

Joliffe, W. (2007). Cooperative Learning in the Classroom. Putting it into Practice. London: Paul Chapman 
Publishing.

Jordan, A. (2010). Creativity in the Classroom. London: Routledge.

Jones, L. (2007). The Student-Centered Classroom. Cambridge University Press.

Kagan, S. (2009). Kagan Cooperative Learning. San Clemente: Kagan publishing.

Kagan, S., \& Miguel. (2009). Cooperative Learning. San Clemente: Kagan publishing.

Lynch, T. (1996). Communication in the Language Classroom. Oxford: Oxford University press.

Watkins, C., Carnell, E., \& Lodge, C. (2007). Effective Learning in Classrooms. London: Paul Chapman Publishing. https://doi.org/10.4135/9781446211472

Yorkey, C. R. (1982). Study Skills for Students of English. USA: McGraw-Hill.

\section{Copyrights}

Copyright for this article is retained by the author(s), with first publication rights granted to the journal.

This is an open-access article distributed under the terms and conditions of the Creative Commons Attribution license (http://creativecommons.org/licenses/by/4.0/). 